Derogating Innocent Victims: The Effects of Relative versus Absolute Character Judgments

\author{
Rael J. Dawtry ${ }^{*}$ \\ Mitchell J. Callan ${ }^{1}$ \\ James M. Olson² \\ Annelie J. Harvey ${ }^{3}$ \\ ${ }^{1}$ Dept. of Psychology, University of Essex, United Kingdom \\ ${ }^{2}$ Dept. of Psychology, University of Western Ontario, Canada \\ ${ }^{3}$ Dept. of Psychology, Anglia Ruskin University, United Kingdom
}

WORD COUNT: 9,993

Authors' note: Address correspondence to Rael Dawtry (rjdawt@essex.ac.uk). This research was funded by a research project grant from the Leverhulme Trust (RPG-2015-387). 


\begin{abstract}
Drawing on just-world theory and research into the suppression and justification of prejudice, we propose that the use of relative compared to absolute measures of an innocent victim's character enables observers to derogate the victim without transparently violating social norms or values proscribing derogation. In Study 1, we found that positive feelings expressed toward victims mirrored social norms proscribing negative reactions toward them. In Studies 2a, 2b and 3, innocent victims were evaluated more negatively when ratings were made using relative (i.e., compared to evaluations of the average student or the self) versus absolute scales. In Study 4, this effect of scale type on derogation was stronger for people higher in the motivation to avoid prejudiced reactions to victims. Relative judgments seem to allow individuals to enact their counter-normative motivation to derogate the victim under the cover of ambiguity and ostensibly rationally motivated social comparison processes.
\end{abstract}

Keywords: victim derogation, social norms, social comparison, relative measures, prejudice 


\section{Derogating Innocent Victims: The Effects of Relative versus Absolute Character Judgments}

One of the most striking of observers' reactions to undeserved suffering and misfortune is the tendency, at times, to derogate the victim's character (e.g., Lerner \& Simmons, 1966; Ryan, 1971). The capacity for people to derogate innocent victims is surprising because, by commonly accepted conventions and social norms, people ought not to derogate someone for negative outcomes brought about by factors beyond their control (Weiner, 1995). One explanation for why people might derogate an innocent victim is that doing so enables them to maintain a belief in a just world (BJW; Lerner, 1980). According to just-world theory, people need to believe that the world is a just and fair place where people get what they deserve. Committing to a just-world is functional because it allows people to pursue longterm goals with confidence (Callan, Harvey, Dawtry, \& Sutton, 2013; Hafer \& Bègue, 2005). Given its functional importance, when the BJW is threatened, such as by witnessing an innocent person suffer, people are motivated to engage in behaviors that restore justice, such as helping the victim or punishing the perpetrators (for reviews, see Ellard, Harvey, \& Callan, 2016; Hafer \& Begue, 2005). When such means of restoring justice are unavailable or too costly, people may instead seek to maintain a perception of deservingness by, for example, derogating the victim's character-in a just-world, bad thing happen only to "bad" people.

\section{Social Norms and Reactions to Victims}

Although research has shown that innocent victims are sometimes rated less favorably than non-victims, derogation rarely manifests as unambiguous, outright negativity. Rather than judging a victim as "bad" per se, derogation generally entails judging a victim neutrally, or as "good" on average, if somewhat less good than if their suffering were lesser or did not occur. Indeed, participants' judgments of a victim's character are often quite positive, with mean character ratings above scale mid-points often observed across both low and high BJW-threatening (e.g., low vs. high suffering) experimental conditions (e.g., Callan, Powell, \& Ellard, 2007; Burczyk \& Standing, 1989; Correia \& Vala, 2003).

What might account for this propensity for observers to evaluate victims positively? One possibility is that character judgements are colored by social norms and values prescribing positive reactions toward innocent victims, and proscribing negative reactions. Social convention holds that it is wrong to derogate a person for suffering brought about through no fault of their own, and a person doing so publically risks being seen as uncaring, vindictive, or irrational by others. Instead, many instances of undeserved suffering elicit expressions of sympathy (Feather, 2006; Weiner, 1995), and reactions of this kind appear to represent the normatively appropriate response toward innocent victims. Indeed, the notion that suffering should be met with sympathy and compassion is reflected by social institutions (e.g., organized religion, humanitarian organizations) and practices (e.g., charitable giving, sympathy cards), and responses of this character frequently occur in the 
wake of highly publicized tragedies (e.g., the 9/11 attacks; the 2011 Tōhoku earthquake and tsunami).

Presumably, via socialization, children learn how conventional rules determine the normatively appropriate response to one's own and others (deserved and undeserved) outcomes (Lerner, 1987), including the appropriate emotional reactions (Feather, 2006; Saarni, 1999). For example, a child may be encouraged to respond with sympathy to a peer who is injured in the playground, or alternatively, they may be sanctioned for teasing a child who is physically disabled. Through experiences of this kind, then, people are taught that positive, other-regarding emotional expressions (e.g., sympathy, compassion) and behavior (e.g., helping, providing reassurance) represent the appropriate and socially normative response to others' undeserved suffering and misfortune.

That reactions to victims are often characterized by sympathy and compassion leads to the question of why, in some situations at least, people instead respond by derogating victims. Lerner $(1998,2003)$ proposes that this paradox can be explained by the operation of two distinct modes of processing and responding to injustice that are differentially engaged depending on contextual factors. One mode involves the automatic application of primitive causal schemas, acquired in early childhood, comprised of simple univalent associations between people and outcomes (e.g., "bad things happen to bad people"). At other times, however, people's reactions will instead follow from a relatively dispassionate, thoughtful and conscious appraisal of the circumstances, which obeys conventional rules for assigning blame and deserving. Deliberation over the causal antecedents of suffering (external circumstances vs. the victim's behavior) triggers attributions of responsibility (blamelessness vs. blameworthiness of the victim), which serve, in turn, to elicit the normatively appropriate emotional reactions (sympathy vs. anger or schadenfreude; Feather, 2006; Weiner, 1993, 1995).

Conformity to social norms should result in relatively favorable character judgments insofar as these norms dictate that people should act in a generally positive manner toward innocent victims, such as by saying positive things about them and refraining from blame or criticism. Irrespective of any underlying motivation to derogate, people might thus respond in overtly positive terms because they do not want to appear deviant or irrational, perhaps to themselves as well as to others (Lerner, 2003). This suggestion echoes research showing that the expression of prejudice mirrors prevailing social norms regarding the acceptability of prejudiced attitudes (e.g., Crandall, Eshleman, \& O'Brien, 2002; Stangor, Sechrist, \& Jost, 2001). The extent to which prejudice is overtly expressed depends upon the normative acceptability of doing so toward a particular target, and in a given context, as well as personal standards regarding the acceptability of prejudice (for a review, see Crandall \& Eshleman, 2003). The same or similar mechanisms may play a role in regulating how people respond toward innocent victims.

Research in the domain of prejudice highlights that, although overt behavior toward a given social (e.g., ethnic) group may comply with social norms, a person's private attitudes need not coincide. People may simply refrain from publicly expressing privately held 
prejudices when doing so would violate social norms. In subtle prejudice, for example, people overtly comply with anti-prejudice social norms and avoid expressing negative attitudes toward minority groups, but subtle, covert expressions of prejudice still emerge in ambiguous situations because these norms are not mirrored by private attitudes (Meertens \& Pettigrew, 1997). As an example, a person holding negative attitudes towards people with disabilities might support segregated schooling for disabled children, masked by the seemingly positive justification that segregation allows for a higher quality education for children with special educational needs (Deal, 2007). To complicate matters further, people can also hold personal standards or values that motivate them to conceal their underlying prejudices from themselves as well as others (Crandall, Eshleman, \& O'Brien, 2002; Devine \& Monteith, 1993; Dunton \& Fazio, 1997).

We suggest that a similar state of affairs might hold for people's reactions to innocent victims. Social norms or personal standards proscribing negativity toward victims might discourage observers from openly expressing negative character judgments, even if they privately hold these views. Following this reasoning, derogation of an innocent victim should be more evident in contexts where normative pressures are reduced or when researchers employ forms of measurement that are less susceptible to socially desirable responding.

\section{Relative and Absolute Measures}

Self-report measures (e.g., Likert-type scales, semantic differentials) typically require respondents to make evaluative judgments (e.g., of attitudes, personality traits, performance) about the self, other persons, or groups in strictly absolute terms. For example, respondents may be asked to indicate the strength of an attitude on a scale ranging from strongly disagree to strongly agree, or to locate another person along a bipolar trait dimension such as very friendly to very unfriendly. Relative ratings, on the other hand, require evaluative judgments to be made in comparison to other individuals or groups (Goffin \& Olson, 2011). Respondents may be asked to indicate whether a target person ranks higher or lower on some attribute (e.g., intelligence) than another person (e.g., the self), or the extent to which they endorse an attitude (e.g., "exams are stressful") compared to a relevant reference group (e.g., "the average student").

We suggest that, when absolute and relative measures are employed in the same context, they may potentially paint different pictures of people's underlying motivation to derogate victims. Our reasoning revolves around the role of social norms and personal standards in shaping overt reactions toward victims, as discussed earlier. Specifically, relative compared to absolute measures are perhaps less susceptible to the influence of social norms or personal standards that compel respondents to evaluate victims positively, in turn muting victim derogation. To illustrate why this may be so, consider the following example. A person is asked to rate their overall impression of Sarah, a hit-and-run victim, on an 11-point scale anchored from $1=$ Very negatively, through $6=$ Neither negatively nor 
positively, to $11=$ Very positively. Insofar as social norms mandate positivity toward innocent victims, a response at (and certainly below) the scale midpoint is inappropriate. Given the anchoring of the scale, such a response unambiguously entails an absence of positive feelings toward the victim. Rather, social norms entail that responses should fall more toward the positive end of the scale.

Now consider that the same person is asked to rate their overall impression of Sarah on an 11-point relative scale that is anchored from 1 = Much more negatively than me, through $6=$ The same as me, to $11=$ Much more positively than me. What, for a naïve outside observer, does a response at the scale midpoint suggest about the judge's underlying feelings toward Sarah? The person's true feelings towards Sarah are ambiguous insofar as the judge's self-evaluation, the reference point from which the victim is evaluated, remains unknown. A response at the midpoint could reflect either positive or negative feelings toward the victim, but the valence and extent of those feelings cannot be reliably determined without knowledge of the judge's feelings about themselves. Hence, when Sarah is evaluated on the relative scale, responses at or close to the midpoint are not clearly unsympathetic and counter-normative.

In sum, we suggest that, because relative measures render underlying evaluations of a victim more ambiguous, they may allow for victim derogation to emerge without transparently violating social norms or personal standards that prohibit negative reactions toward victims. In a similar way that implicit measures often suggest that underlying prejudice is higher than do explicit self-reports (e.g., Crosby, Bromley, \& Saxe, 1980; Dunton $\&$ Fazio, 1997), relative measures may reveal that the underlying motivation to derogate an innocent victim is stronger than is suggested by absolute measures in the same context.

\section{The Current Research}

We investigated the role played by absolute versus relative ratings, and social norms, in victim derogation across five studies. In Study 1, we examined whether the normative acceptability of expressing negative feelings toward victims is related to the evaluations that victims and other social groups receive. In Studies $2 a$ and $2 b$, we investigated whether scale type (i.e., absolute versus relative) affected the extent of victim derogation for an innocent victim (i.e., high just world threat) versus a non-innocent victim (i.e., low just world threat). In Study 3, we followed up our Study 2 findings by using an alternative manipulation (fortunate vs. unfortunate outcomes). Finally, in Study 4, we investigated whether the motivation to avoid negative reactions toward victims modulates differences between absolute and relative measures of an innocent victim's character.

\section{Study 1}

Although we suggested that it is counter-normative to derogate victims, to our knowledge no previous research has directly examined prescriptive social norms regarding reactions 
toward victims. To address this, in Study 1 we asked participants about the normative acceptability of expressing negative feelings toward different victim (and non-victim) groups. Relatedly, research has shown that the extent to which negative feelings are expressed toward a given social group is strongly related to the normative acceptability of doing so, underscoring that social norms play a powerful role in regulating the expression of prejudice (Crandall, Eshleman, \& O'Brien, 2002). Our reasoning suggests that social norms play an equivalent role in regulating the expression of victim derogation. Hence, we examined the idea that normative acceptability is negatively related to the evaluations that victims and other groups receive.

\section{Method}

Participants. Participants $\left(N=83 ; 47 \%\right.$ female; $\left.M_{\text {age }}=34.2\right)$ were residents of the United Kingdom recruited online via Prolific Academic (Peer, Brandimarte, Samat \& Acquisti, 2016). ${ }^{1}$

Materials. The complete materials for all studies are available in the online supplementary material. The Study 1 materials and procedure closely mirrored those used by Crandall, Eshleman, and O'Brien (2002, Study 1). First, we adapted the list of 105 social groups used by Crandall et al. to better suit our purposes. A number of groups were dropped completely from the list either because (a) they were somewhat outdated and may not have been recognized (e.g., Guests on Ricki Lake), or (b) they were deemed not relevant to participants in the UK (e.g., Members of the National Rifle Association). Several others were replaced with similar groups that were deemed more relevant to participants in the UK (e.g., Hispanics was replaced with Eastern Europeans). We then added 6 victim groups to the list, namely, cancer patients, assault victims, victims of freak accidents, hit and run victims, robbery victims, and people suffering infectious diseases. A seventh victim group, people with AIDS, was already contained in the original list generated by Crandall et al. and was retained. The final list, then, was comprised of 100 groups, 7 of which were differing categories of victim. We aimed to use victim groups that were representative of those typically used in experimental research on victim derogation. Note, however, that a number of additional groups contained in Crandall et al.'s (2002) stimuli, and which were retained, can also be considered victims insofar as they are construed as suffering undeservedly (e.g., people who are blind). Alternatively, these groups might be considered as qualitatively distinct from other victims, insofar as they could involve disabilities that a person is born with, and such persons may not consider themselves to be victims. This ambiguity underscores the inherent "fuzziness" of the victim concept-who is considered to be a "victim" likely varies across people and contexts.

\footnotetext{
${ }^{1}$ We did not request participants' race/ethnicity. Descriptions of the relevant participant pool compositions are available in Peer et al. (2016) for Study 1, and in Buhrmester et al. (2011) for Studies 2-4.
} 
Procedure. Participants first rated the "normative acceptability of expressing negative feelings" toward each of the 100 groups ( 1 = Definitely not OK to express negative feelings about this group; 5 = Definitely OK to express negative feelings about this group). The presentation order of groups was fully randomized across participants, who were additionally instructed that their responses should reflect what people generally agree is acceptable rather than their own personal opinions.

On a separate page, participants rated their personal feelings toward each of the 100 groups using feeling thermometers $(0=$ Cold/Not positive; $100=$ Hot $/$ Very positive $)$. The order of groups was again fully randomized across participants.

\section{Results and Discussion}

Table 1 shows the 100 groups ordered by mean normative acceptability scores. All seven victim groups were rated below the scale midpoint (all $p s<.001$ ), indicating that participants believed it is socially unacceptable to express negative feelings toward any of the victim groups included. Averaging across all seven, victims in general were ranked as the $8^{\text {th }}$ least acceptable group (of 94 ) to express negativity toward $(M=1.47, S D=0.66)$, and evoked warm feelings $(M=72.33, S D=18.81)$.

We then calculated the mean normative acceptability ratings and feeling thermometer scores, collapsed across participants, for each of the 100 groups. Treating the groups as individual observations, the correlation between mean normative acceptability ratings and feelings was $r=-.97,95 \% \mathrm{Cl}[-.95,-.98]$, indicating that the extent to which participants expressed negativity toward any given group was very strongly related to the normative acceptability of doing so. This relation also held true for victim groups at the participant-level observations; collapsing across the seven victim groups, the correlation between normative acceptability ratings $(\alpha=.85)$ and feelings toward victims $(\alpha=.92)$ was $r$ $=-.36,95 \% \mathrm{Cl}[-.14,-.55]$.

The Study 1 findings underscore that social norms proscribe the expression of negative feelings toward various types of victims. Echoing previous findings showing that the expression of prejudice mirrors prevailing social norms (Crandall et al., 2002), less (more) acceptable targets of negative feelings evoked more (less) positive feelings, and this was the case for social groups in general, as well as victims specifically. To the extent that people are chronically or situationally motivated to follow social norms when evaluating a victim, then, they presumably ought to avoid openly engaging in victim derogation. 


\begin{tabular}{|c|c|c|c|c|c|c|c|c|}
\hline $\begin{array}{l}\text { Normative } \\
\text { acceptability }\end{array}$ & Feelings & Social group & (cont.) & (cont.) & (cont.) & (cont.) & (cont.) & (cont.) \\
\hline $1.18(0.59)$ & $77.78(23.77)$ & Cancer patients* & $1.98(1.09)$ & $68.49(22.20)$ & Manual laborers & $3.12(1.18)$ & $36.00(23.45)$ & Porn stars \\
\hline $1.19(0.48)$ & $74.45(24.04)$ & Blind people & $1.99(1.10)$ & $57.41(21.16)$ & People who are illiterate & $3.13(1.35)$ & $35.77(24.84)$ & Smokers \\
\hline $1.30(0.68)$ & $76.14(24.15)$ & Paralympic athletes & $2.00(1.15)$ & $64.96(28.31)$ & Eastern Europeans & $3.14(1.37)$ & $37.35(21.43)$ & Ultra-thin fashion models \\
\hline $1.30(0.66)$ & $75.31(23.29)$ & Deaf people & $2.02(1.19)$ & $46.55(22.81)$ & People with open sores & $3.18(1.38)$ & $35.33(23.25)$ & Debt collectors \\
\hline $1.34(0.77)$ & $76.20(22.52)$ & Assault victims* & $2.06(1.18)$ & $69.77(25.56)$ & People from the north of England & $3.23(1.24)$ & $39.62(19.10)$ & Students who rarely study \\
\hline $1.35(0.71)$ & $73.00(22.60)$ & Victims of freak accidents* & $2.08(1.15)$ & $59.18(24.49)$ & Homeless people & $3.23(1.36)$ & $25.19(19.38)$ & Members of religious cults \\
\hline $1.39(0.71)$ & $72.01(24.21)$ & Mentally disabled people & $2.11(1.27)$ & $69.57(24.86)$ & Cat owners & $3.27(1.28)$ & $28.21(22.91)$ & Men who go to prostitutes \\
\hline $1.41(0.77)$ & $80.57(21.74)$ & Firefighters & $2.16(1.23)$ & $75.37(21.93)$ & Doctors & $3.36(1.39)$ & $31.04(19.00)$ & Door to door salesmen \\
\hline $1.44(0.82)$ & $72.81(24.07)$ & Mixed race couples & $2.17(1.09)$ & $63.65(23.77)$ & Farmers & $3.36(1.32)$ & $25.65(24.18)$ & Members of UKIP ${ }^{+}$ \\
\hline $1.46(1.00)$ & $77.75(21.64)$ & Hit and run victims* & $2.20(1.18)$ & $57.81(22.70)$ & People from Essex & $3.41(1.19)$ & $27.45(20.59)$ & Youth offenders \\
\hline $1.47(0.87)$ & $66.71(27.79)$ & Army veterans & $2.24(1.26)$ & $58.41(25.71)$ & Feminists & $3.46(1.27)$ & $35.33(21.15)$ & Lazy people \\
\hline $1.50(0.84)$ & $67.91(24.89)$ & Mentally ill people & $2.28(1.26)$ & $62.88(27.55)$ & Police officers & $3.49(1.37)$ & $27.77(25.05)$ & Drug users \\
\hline $1.52(0.90)$ & $73.40(25.80)$ & Black people & $2.29(1.24)$ & $67.20(23.00)$ & University students & $3.58(1.13)$ & $21.71(21.40)$ & Men who leave their families \\
\hline $1.53(0.83)$ & $69.31(27.61)$ & Gay soldiers & $2.29(1.12)$ & $63.66(25.01)$ & Environmentalists & $3.64(1.20)$ & $28.24(26.45)$ & People who sell cannabis \\
\hline $1.53(0.90)$ & $68.65(26.37)$ & Jews & $2.31(1.28)$ & $52.43(22.57)$ & Pub darts players & 3.65 (1.39) & $22.25(26.04)$ & Members of the BNP ${ }^{++}$ \\
\hline $1.58(0.95)$ & $70.24(25.79)$ & Asians & $2.32(1.21)$ & $61.55(23.68)$ & Civil servants & $3.71(1.20)$ & $33.30(22.54)$ & Politicians \\
\hline $1.60(1.03)$ & $73.29(22.79)$ & Robbery victims* & $2.32(1.29)$ & $55.76(24.28)$ & Folk music fans & $3.78(1.26)$ & $22.15(24.29)$ & Pregnant women who drink alcohol \\
\hline $1.60(0.91)$ & $65.25(27.81)$ & Buddhists & $2.35(1.24)$ & $64.10(24.22)$ & College students & $3.84(1.14)$ & $22.47(19.84)$ & People who cheat on exams \\
\hline $1.61(0.94)$ & $63.45(25.59)$ & People with AIDS* & $2.39(1.28)$ & $61.73(21.48)$ & Car mechanics & $3.87(1.12)$ & $19.55(16.30)$ & Kids who steal other kids lunch money \\
\hline $1.64(0.89)$ & $70.38(26.52)$ & Elderly people & $2.42(1.26)$ & $59.77(23.43)$ & Accountants & $3.88(1.06)$ & $21.24(18.85)$ & People who litter \\
\hline $1.69(1.02)$ & $77.20(23.04)$ & Male nurses & $2.45(1.26)$ & $52.78(24.21)$ & Fat people & $3.89(1.22)$ & $21.43(16.25)$ & People who cut in line \\
\hline $1.71(1.13)$ & $70.34(28.56)$ & Gay people who raise children & $2.45(1.22)$ & $47.96(21.43)$ & Beauty contestants & $3.95(0.99)$ & $20.38(19.51)$ & Liars \\
\hline $1.76(0.93)$ & $62.93(23.64)$ & People on disability benefits & $2.46(1.20)$ & $51.00(22.42)$ & Benefits claimants & $3.98(1.10)$ & $22.47(19.84)$ & People who cheat on their partners \\
\hline $1.76(1.03)$ & $61.42(25.35)$ & Ugly people & $2.66(1.37)$ & $33.64(24.80)$ & Jehovah's witnesses & $3.98(1.15)$ & $14.32(19.17)$ & Negligent parents \\
\hline $1.80(1.03)$ & $74.51(23.31)$ & Business women & $2.73(1.40)$ & $57.27(24.80)$ & Lawyers & $4.01(1.08)$ & $17.78(19.32)$ & Men who refuse to pay child support \\
\hline $1.80(1.13)$ & $73.82(23.42)$ & Canadians & $2.76(1.24)$ & $41.35(21.50)$ & Ex-prisoners & $4.05(1.13)$ & $15.96(20.94)$ & Gang members \\
\hline $1.86(1.03)$ & $69.59(21.88)$ & Housewives & $2.79(1.42)$ & $36.70(25.46)$ & Male prostitutes & $4.12(1.17)$ & $16.14(20.02)$ & Careless drivers \\
\hline $1.87(1.16)$ & $55.95(22.68)$ & People suffering infectious diseases* & $2.84(1.38)$ & $38.60(24.45)$ & Female prostitutes & $4.36(1.13)$ & $8.73(19.16)$ & Racists \\
\hline $1.87(0.91)$ & $58.65(21.17)$ & People who put their kids in day-care & $2.93(1.36)$ & $41.09(28.42)$ & Illegal immigrants & $4.56(0.85)$ & $6.22(19.60)$ & Terrorists \\
\hline $1.92(1.13)$ & $69.46(22.91)$ & Charity workers & $2.94(1.27)$ & 33.35 (23.19) & Alcoholics & $4.60(0.84)$ & $5.97(16.51)$ & Wife beaters \\
\hline $1.95(1.24)$ & $70.31(25.94)$ & White people & $3.02(1.41)$ & $39.42(27.59)$ & Brexit voters & $4.60(0.92)$ & $5.07(18.05)$ & Pedophiles \\
\hline $1.95(1.11)$ & $68.32(23.83)$ & Librarians & $3.08(1.15)$ & $33.79(21.84)$ & People who smell bad & $4.63(0.87)$ & $5.20(18.95)$ & Rapists \\
\hline \multirow[t]{2}{*}{$1.95(1.19)$} & $53.84(27.87)$ & Catholics & $3.11(1.13)$ & $34.59(20.91$ & Gamblers & $4.66(0.79$ & $6.70(16.78)$ & Drunk drivers \\
\hline & & & & & & $4.69(0.83)$ & $5.60(18.20)$ & Child abusers \\
\hline
\end{tabular}


Note. Victim groups*. Higher Scores $=$ greater normative acceptability of expressing negative attitudes. ${ }^{\dagger}$ United Kingdom Independence Party. ${ }^{+\dagger}$ British National Party.

Table 1. Mean (SD) normative acceptability of expressing negative feelings toward, and feelings toward, 100 social groups 


\section{Studies $2 a$ and $2 b$}

In Studies $2 \mathrm{a}$ and $2 \mathrm{~b}$, we examined whether evaluations of an innocent (vs. non-innocent) victim's character vary depending on the type of response scale used (relative vs. absolute). Although observers tend to rate non-innocent victims unfavorably, this does not represent victim derogation motivated by a concern for justice per se, but simply reflects that victims are held responsible for suffering brought about by their own actions, in accordance with normative rules for assigning blame and deserving (Hafer \& Begue, 2005). Because negative reactions are normative and easily justified when a victim's suffering is deserved, our reasoning suggests that little or no difference is to be expected between relative and absolute ratings for non-innocent victims. Insofar as participants use victim derogation to restore a perception of deservingness when exposed to an innocent victim, however, our reasoning suggests that relative compared to absolute measures will facilitate higher levels of victim derogation. Hence varying the innocence of the victim allowed us to test whether relative and absolute ratings differ, and crucially, whether they differ only under conditions in which, from just-world theory, derogation would be expected to occur-that is, when the victim is innocent (Callan, Shead, \& Olson, 2009; Correia \& Vala, 2003; Harvey, Callan, \& Matthews, 2014).

Studies $2 \mathrm{a}$ and $2 \mathrm{~b}$ were identical with the exception of the comparison target used for the relative scales (victim compared to the average university student/the self, respectively). We employed different comparison targets across the two studies to ascertain whether results depended upon the particular referent employed in relative ratings.

\section{Method}

Participants. Participants in Studies 2a $\left(N=200 ; 46 \%\right.$ female; $\left.M_{\text {age }}=33.9\right)$ and $2 b(N$ $=207 ; 42 \%$ female; $M_{\text {age }}=34.33$ ) were from the United States and recruited online via Amazon's Mechanical Turk (Buhrmester, Kwang \& Gosling, 2011). A further 28 participants in Study 2a, and 18 in Study 2b, were excluded for duplicate IP addresses or incorrectly answering a scenario comprehension check. The required sample sizes were set ahead of data collection (but were not completely predetermined due to removals and slight overrecruitment), and power analyses showed that we had $80 \%$ power to detect "medium" effect sizes $(f=.20, \alpha=.05)$ for Studies $2 a$ and $2 b$.

Materials and procedure. In both Studies $2 \mathrm{a}$ and $2 \mathrm{~b}$, participants were presented with a brief, ostensibly real news excerpt describing an incident where a male university student, called James, was injured after being hit by a car while attempting to cross the street (Callan, Dawtry \& Olson, 2012). Half the participants were told that James "was crossing the road and the 'walk' sign was illuminated when he was struck by a driver going through a red light" (innocent victim). The remaining participants learned that James "was 
crossing the road and the 'do not walk' sign was illuminated when he was struck by a driver going through a green light" (non-innocent).

Participants then responded to three separate items regarding their impression of James's character. Half of the participants in both Studies $2 a$ and $2 b$ rated James's character on absolute scales. These participants were asked to "Please rate James in terms of how careless/irresponsible/foolish he is as a person" $(0=$ not at all careless/irresponsible/foolish to $100=$ a great deal careless/irresponsible/foolish; rescored 1-11 for analysis across measures and studies).

In Study 2a, the remaining participants were presented with the same three questions, but in relation to the average university student. That is, participants were asked "Please rate James in terms of how careless/irresponsible/foolish he is as a person compared to the average university student" $(0=$ not at all careless/irresponsible/foolish compared to the average university student to $100=$ a great deal careless/irresponsible/foolish compared to the average university student).

In Study $2 b$, the remaining participants were presented with the same three questions in relation to themselves. Participants were asked "Please rate James in terms of how careless/irresponsible/foolish he is as a person compared to how careless/irresponsible/foolish you are as a person" $(0=$ not at all careless/irresponsible/foolish compared to me to $100=$ a great deal careless/irresponsible/foolish compared to me).

A value of 50 on the relative scales corresponded to a judgment that James was "about the same" as the average university student/me. The items were averaged, separately in Studies $2 a$ and $2 b$, to form composite absolute and relative measures of victim derogation. The measures achieved good internal consistency in both Studies $2 a$ and $2 b$ (all as > .98).

In both Studies $2 \mathrm{a}$ and $2 \mathrm{~b}$, immediately following the relative or absolute character rating items, participants responded to an open-ended question in which they were requested to "...provide a few sentences about how you answered these questions." Following Olson, Goffin, and Haynes (2007), participants were asked "How did you come up with your answers? What thoughts went through your mind? Why did you choose the responses you did?" Finally, participants in both studies answered a manipulation check ("I feel what happened to James is"; 1 = Slightly unfair to 7 = A great deal unfair) and an attention check ("In the news story you read, did the driver that hit James run a red light?"; Yes, No, Can't remember, Didn't say) before providing demographic information.

\section{Results}

Manipulation checks. Confirming the success of the innocence manipulation, participants in Study 2a perceived the event as more unfair when James was innocent $(M=$ $5.75, S D=1.84)$ than when he was non-innocent $(M=2.88, S D=1.68), t(194.91)=11.48, p<$ .001 (here and throughout, degrees of freedom were Welch-corrected where applicable; 
see Delacre, Lakens, \& Leys, in press). Similarly, participants in Study $2 \mathrm{~b}$ rated the situation as more unfair when James was innocent $(M=6.00, S D=1.54)$ than non-innocent $(M=2.77$, $S D=1.53), t(203.92)=15.11, p<.001$.

Ratings of the victim's character. In Study 2a, a 2 (innocence: innocent vs. non innocent) by 2 (scale type: absolute vs. relative) between-subjects ANOVA revealed a significant main effect for victim innocence, with participants rating the victim more negatively when he was not innocent than when he was innocent, $F(1,196)=434.51, p<$ $.001, n p^{2}=.689$. There was also a significant interaction between victim innocence and scale type, $F(1,196)=17.88, p<.001, n p^{2}=.084$ (see Table 2). Follow-up $t$-tests revealed that when the victim was innocent, participants who responded in relative terms (compared to the average university student) rated James more negatively than participants who responded in absolute terms, $t(96.56)=3.43, p<.001, d=0.68,95 \% \mathrm{Cl}$ of $d[0.27,1.07]$. This pattern was reversed when the victim was non-innocent, $t(78.72)=-2.45, p=.017, d=-$ $0.51,95 \% \mathrm{Cl}$ of $d[-0.91,-0.10]$.

In Study $2 b$, there was a significant main effect for victim innocence, with participants devaluing the victim more when he was not innocent than when he was innocent, $F(1,203)=283.07, p<.001, n p^{2}=.582$. There was also a significant main effect of scale type, with participants rating the victim more negatively when responding in relative (compared to the self) versus absolute terms, $F(1,203)=18.63, p<.001, n p^{2}=.084$. These main effects were qualified by a significant interaction, $F(1,203)=7.97, p=.005, n p^{2}=.038$ (see Figure 2). Follow-up tests revealed that when presented with the suffering of an innocent victim, participants who responded in relative (vs. absolute) terms rated the victim more negatively, $t(96.21)=4.13, p<.001, d=0.82,95 \% \mathrm{Cl}$ of $d[0.41,1.22]$. When the victim was non-innocent, there was no significant difference between type of ratings, $t(97.67)=$ $1.43, p=.16, d=0.28,95 \% \mathrm{Cl}$ of $d[-.10,0.66]$.

Taken together, the results of Study $2 \mathrm{a}$ and $2 \mathrm{~b}$ demonstrated that participants rated the victim's character more negatively when their ratings were made in relative versus absolute terms but only when the victim was innocent. ${ }^{2}$

\footnotetext{
${ }^{2}$ An analysis of the data standardized within and collated across Studies $2 \mathrm{a}$ and $2 \mathrm{~b}$ found that the Innocence $\mathrm{X}$ Rating Type interaction, $F(1,399)=24.02, p<.001, n p^{2}=.057$, did not differ significantly by rating type (i.e., there was no significant three-way interaction), $F(1,399)=0.46, p=.50, n p^{2}=.001$.
} 
Table 2. Descriptive statistics for Studies $2 a$ and $2 b$

\begin{tabular}{|c|c|c|c|c|c|c|}
\hline \multirow{3}{*}{ Rating Type } & \multicolumn{6}{|c|}{ Victim Innocence } \\
\hline & \multicolumn{3}{|c|}{ Innocent } & \multicolumn{3}{|c|}{ Non-Innocent } \\
\hline & $M$ & $S D$ & $95 \% \mathrm{Cl}$ of $M$ & $M$ & $S D$ & $95 \% \mathrm{Cl}$ of $M$ \\
\hline \multicolumn{7}{|l|}{ Study $2 a$} \\
\hline Relative & 3.79 & 2.39 & {$[3.14,4.44]$} & 8.31 & 1.82 & {$[7.77,8.85]$} \\
\hline Absolute & 2.31 & 1.95 & {$[1.76,2.86]$} & 9.13 & 1.39 & {$[8.77,9.49]$} \\
\hline \multicolumn{7}{|l|}{ Study 2 b } \\
\hline Relative & 5.41 & 2.28 & {$[4.83,5.99]$} & 9.04 & 1.64 & {$[8.58,9.50]$} \\
\hline Absolute & 3.15 & 2.57 & {$[2.41,3.89]$} & 8.62 & 1.32 & {$[8.25,8.99]$} \\
\hline
\end{tabular}

Explanations for ratings of the victim's character. Similar to Olson et al. (2007), participants in both studies were requested to write a few sentences about how they responded to the relative or absolute ratings of the victim's character. Our primary interest was the extent to which relative compared to absolute rating scales induced participants to draw social comparisons when evaluating the victim. We adopted a two-category coding scheme: comparisons vs. attributions. Specifically, we coded ( $0=$ No, $1=$ Yes) whether each response made at least one reference to social comparison information (e.g., "He put himself in danger, something I would never do"; "He seemed less careful than peers his age"), and whether the response made at least one (non-comparative) attribution to the victim's thoughts or actions (e.g., "He did everything as he should have"; "He should have been paying more attention").

The resulting counts of comparisons and attributions within the relative and absolute conditions are shown in Table 3. Although attributions were always more frequent, chi-square tests on both the Study $2 a, \chi^{2}(1)=32.22, p<.001$, and Study $2 b, \chi^{2}(1)=54.18, p<$ .001 data, indicated that the ratio of social comparisons to attributions was significantly greater when participants responded using relative (vs. absolute) rating scales. Hence social comparisons were relatively more common amongst participants who rated the victim using relative compared to absolute rating scales. Notably, explanations for absolute ratings rarely mentioned social comparisons, underscoring that absolute ratings do not appear to provoke social comparisons like relative ratings do.

Table 3. Frequencies of open-ended explanations of scale responses referring to attributions and social comparisons by study.

\begin{tabular}{lccccc}
\hline \multirow{2}{*}{ Ratings } & \multicolumn{2}{c}{ Study 2a } & \multicolumn{2}{c}{ Study 2b } \\
& Attributions & Comparisons & Attributions & Comparisons \\
\hline Absolute & 103 & 7 & 102 & 2 \\
Relative & 74 & 45 & 63 & 51 \\
\hline
\end{tabular}




\section{Study 3}

In Studies $2 \mathrm{a}$ and $2 \mathrm{~b}$, relative scales produced more negative evaluations of the victim's character than absolute scales only when the victim was innocent. More specifically, relative (vs. absolute) scales produced more negative evaluations of the victim under conditions where observers would be expected to derogate and where it was counter-normative to do so (i.e., under high just-world threat/when the victim was innocent). The interactions we observed suggest it is not the case that relative scales straightforwardly lead participants to necessarily select higher values in any given victimization context.

One issue with these results is that because mean-levels of derogation in the noninnocent condition approached the scale end-points in both Studies $2 a$ and $2 b$, the observed interactions may have resulted from ceiling effects. That is, higher relative character ratings might conceivably have been observed, possibly reducing or mitigating the interactions, had the scales been able to capture any latent variance in derogation extending beyond the scale end-points.

In Study 3, we sought to address this issue by using a different manipulation of justworld threat. Specifically, participants read several scenarios that described otherwise "neutral" people either being the beneficiaries of a fortuitous positive outcome (low justworld threat; cf. Callan, Kay, \& Dawtry, 2014; Lerner, 1965), or the victims of a fortuitous negative outcome (high just-world threat), and rated the target persons in both relative and absolute terms. This design allowed us to examine whether the interactions observed in Studies $2 \mathrm{a}$ and $2 \mathrm{~b}$ could be replicated in contexts where the person's conduct was not objectively tied to his or her outcome (unlike the "non-innocent" James, who brought about his own suffering by jaywalking).

\section{Method}

Participants. Participants from the US were recruited online via Amazon's Mechanical Turk $\left(N=209 ; 51.7 \%\right.$ female; $\left.M_{\text {age }}=38.6\right)$. Fifteen additional participants were excluded for incorrectly answering a scenario comprehension check.

Materials and procedure. Study 3 used a 2 (Outcome: good vs. bad) x 2 (Rating Type: absolute vs. relative) fully-within subjects design. Participants read four brief scenarios describing two fortunate and two unfortunate events occurring to different people. The good outcome stories described: (a) a woman finding a box of antique coins or (b) a man making a large profit on the stock market. The bad outcome stories described, (a) a woman experiencing a cycling accident and mugging or (b) a man having an unsuccessful kidney transplant.

Following each scenario, participants rated their "overall impression" of the target person on one absolute (e.g., "How negative-to-positive would you evaluate Thomas as a person"; 0 = Very negatively; 10 = Very positively) and one relative item (e.g., "How 
negative-to-positive would you evaluate Thomas as a person compared to how negative-topositive you would evaluate yourself as a person"; 0 = Very negatively compared to me; $10=$ Very positively compared to me; re-scored as 1 to 11 for analysis). Ratings were reverse scored so higher values indicated more negative evaluations of the targets. The ordering of scenarios and relative and absolute responses was fully randomized across participants. Finally, participants answered a simple attention check item: "What happened in the story you read about Barry flicking through a newspaper in the park" ( 1 of the possible 4 answers was correct).

\section{Results}

Participants' ratings of the targets were fit with a linear mixed effects model using the Ime4 package (Bates, Maechler, Bolker, \& Walker, 2015, version 1.1-12) in R (R Core Team, 2015, version 3.3.2). The model included fixed effects for Outcome (good vs. bad, coded -0.5 and +0.5 ), Rating Type (absolute vs. relative, coded -0.5 and +0.5 ) and the Outcome X Rating Type interaction. We included random intercepts for participants and scenarios, and random slopes by participants for the effects of Outcome, Rating Type and the Outcome $X$ Rating Type interaction (i.e., we allowed the main effects and the interaction to vary across participants, and random effects were correlated). ${ }^{3}$ To determine statistical significance of the fixed effects, we used Satterthwaite approximations to calculate $p$-values using the ImerTest package (Kuznetsova, Brockhoff, \& Christensen, 2015) along with reporting 95\% Wald confidence intervals.

Shown in Figure 1, analyses revealed a significant main effect for Rating Type, $b=$ 1.05 , se $=0.09,95 \%$ Wald $\mathrm{Cl}[0.87,1.23] ; t(211.70)=11.54, p<.001$, but not for Outcome, $b$ $=0.44$, se $=0.29,95 \%$ Wald Cl $[-0.13,1.00] ; t(2.90)=1.51, p=.23$. More importantly, there was a significant Outcome $X$ Rating Type interaction, $b=0.39$, se $=0.138,95 \%$ Wald $\mathrm{Cl}[0.12$, $0.66] ; t(643.10)=2.83, p=.005 .{ }^{4}$ Follow-up analyses by refitting the model using dummy coding revealed that participants evaluated the targets more negatively using relative (vs. absolute) scales more strongly when the outcome was bad, $b=1.24$, se $=0.12,95 \% \mathrm{Wald} \mathrm{Cl}$ $[1.00,1.48] ; t(227.50)=10.18, p<.001$, than when the outcome was good, $b=0.85$, se $=$ $0.10,95 \%$ Wald Cl $[0.65,1.06] ; t(350.20)=8.11, p<.001$. Therefore, relative scales

\footnotetext{
${ }^{3} \mathrm{~A}$ likelihood ratio test showed that a model including by-scenario random slopes for Rating Type did not produce a better fit than the simpler model, $\chi^{2}(2)=0.95, p=.65$ (Judd, Westfall, \& Kenny, 2012). Because each scenario was associated only with one type of outcome, we did not test a model including by-scenario random slopes for Outcome or the Outcome X Rating Type interaction.

${ }^{4}$ The same analyses but also including the order participants completed the relative and absolute scales (absolute first vs. relative first, coded +0.5 and -0.5 ) and the random slope by participants for the effect of order did not reveal a significant effect of order, $b=-0.17$, se $=0.11,95 \%$ Wald Cl $[-0.35,0.08] ; t(184.30)=-$ $1.24, p=.22$.
} 
produced more derogation of the targets to a greater extent in response to bad (vs. good) outcomes.

Interestingly, participants nonetheless rated the targets more negatively relative to the self even when the outcome was good. We speculate that social norms (such as norms of politeness; e.g., DeBono, Shmueli \& Muraven, 2011) might entail that, where diagnostic information about a person is lacking, they should be given "the benefit of the doubt" and evaluated positively, thus producing favorable absolute ratings irrespective of the outcome a target experiences. Relatedly, people might evaluate any target less favorably relative to the self (or, conversely, evaluate the self favorably relative to any target) in most contexts because of self-enhancement (Brown, 1986; Krueger, 1998).

To examine these possibilities empirically, we conducted a follow-up study with Mechanical Turk participants ( $N=143 ; 51 \%$ female; $M_{\text {age }}=37.3 ; 19$ additional participants were excluded due to duplicate IPs or failing a comprehension check) that was identical to Study 3, with two exceptions: First, the fortunate or unfortunate outcome information was removed, such that participants read only the first sentence describing the target person only (i.e., "Sarah is riding her bicycle home from work one day"; "Michelle is a metal detecting enthusiast"; "Thomas suffers from a rare disease of the kidneys"; Barry is sitting in the park during his lunch break"). Secondly, we included an additional measure in which the targets were judged relative to the average person from the social category they belonged to (e.g., "the average metal detecting enthusiast"). A one-way within-subjects ANOVA revealed that mean evaluations of the target differed across the three scale types, $F(2,284)$ $=52.67, p<.001, n p^{2}=0.27$. Follow up tests revealed that absolute ratings $(M=4.93, S D=$ 1.13) were less negative than relative-to-average ratings $(M=5.57, S D=0.90), t(142)=8.05$, $p<.001, d=0.67,95 \% \mathrm{Cl}$ 's $[0.49,0.85]$, which in turn did not significantly differ from relative-to-self ratings $(M=5.48, S D=0.94), t(142)=1.45, p=.13, d=0.13,95 \%$ Cl's [-0.04, 0.29 ]. Absolute compared to relative ratings, then, were less negative even in the absence of any outcome information. This is not likely due to self-enhancement because relative ratings were always more negative, and similarly so, regardless of whether they did (i.e., when made relative to the self) or did not (i.e., when made relative to the average $X$ ) provide an opportunity to self-enhance. 


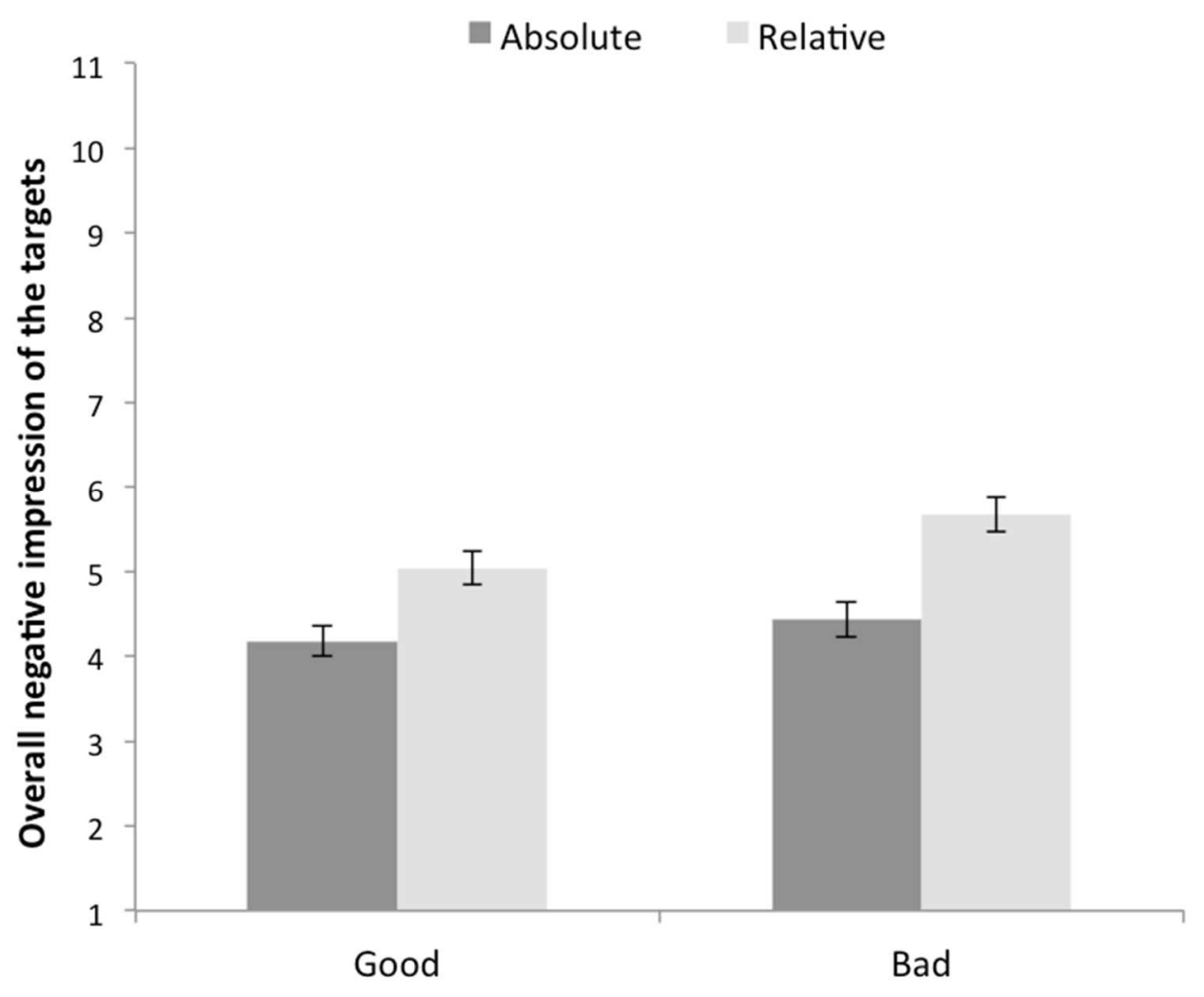

Figure 1. The effect of outcome valence and scale type on derogation in Study 3. Error bars represent Cousineau-Morey 95\% Cls (Baguley, 2012).

\section{Study 4}

Taken together, the findings of Studies $2 \mathrm{a}, 2 \mathrm{~b}$ and 3 suggest that relative ratings produced more negative evaluations of the victim (a) irrespective of the particular nature of the injustice, and (b) to a greater extent under conditions where participants are theoretically motivated to engage in derogation (i.e., under higher just-world threat; innocent victims, fortuitous bad outcomes).

We next turned our attention to one factor that might modulate this divergence between relative and absolute ratings; specifically, the role of sensitivity to social norms or personal values that proscribe derogating innocent victims. Drawing on research and theorizing in the domain of prejudice, we suggest that a motivation to comply with social norms or personal standards proscribing negativity toward victims may modulate the divergence between relative and absolute measures under conditions of high just-world threat.

Crandall and Eshleman (2003) suggested that "raw" prejudice does not manifest directly in behavior-rather, its expression is moderated by contextual or individual factors (social norms, beliefs, values) which can lead to its suppression, and other factors which justify or otherwise allow prejudice to emerge, often in covert form. Individuals may suppress prejudice to publicly comply with anti-prejudice social norms, because they have 
internalized these norms (e.g., Blanchard, Crandall, Brigham \& Vaughn, 1994; Crandall, Eshleman \& O’Brien, 2002), or similarly, because they possess personal values (e.g., egalitarianism, political liberalism) that proscribe prejudice (e.g., Katz \& Hass, 1988). People can be motivated to appear non-prejudiced to other people, themselves, or both, and the chronic motivation to suppress prejudice varies across individuals (Crandall, Eshleman \& O’Brien, 2002; Dunton \& Fazio, 1997). For example, Dunton and Fazio (1997) found that people who scored higher on their Motivation to Control Prejudiced Reactions Scale (MCPRS) expressed less prejudice on explicit measures even when implicit measures revealed negativity toward black targets, whereas low scorers were consistent in their explicit and implicit evaluations. These findings underscore how suppression serves to restrain or prevent implicit prejudice from manifesting in overt responses and behavior.

We suggest that suppression may also play a role in responses toward victims. Social norms prescribe that it is inappropriate to react negatively toward innocent victims (see Study 1), and negative reactions are likely to be seen as callous, irrational, and otherwise undesirable, potentially by the self as well as other persons. To the extent that people internalize or seek to comply with norms mandating sympathy toward victims, any underlying motivation to derogate is potentially suppressed in overt evaluations. Suppression also provides one possible explanation for the higher levels of derogation observed under BJW-threatening conditions with relative (vs. absolute) measures in Studies $2 \mathrm{a}, 2 \mathrm{~b}$ and 3 . Specifically, because relative compared to absolute measures render respondents' underlying attitudes toward the victim somewhat ambiguous to the self or any potential audience, they are perhaps less prone to suppression. We investigated this possibility in Study 4 by examining whether the effect of rating type on victim derogation is modulated by the motivation to avoid reacting negatively toward victims.

\section{Method}

Participants. Participants from the US were recruited online via Amazon's Mechanical Turk ( $N=223 ; 51 \%$ female; $M_{\text {age }}=37.2$ ). An additional 21 participants were excluded either for incorrectly answering an attention check item $(n=10$; "please select strongly disagree"), incorrectly answering a scenario comprehension question ( $n=9$; described below), or having a duplicate IP address $(n=2)$.

Materials and procedure. Participants were recruited to take part in two (ostensibly) separate short surveys on "worldviews" and "impressions of different events and people". They first completed an adapted version of Dunton and Fazio's (1997) MCPRS questionnaire. The wording of items was adapted such that those referring explicitly to suppressing prejudice (MCPRS items 1, 3, 5, 10, 11, 12, 14; e.g., "In today's society it is important that one not be perceived as prejudiced in any manner") referred instead to suppressing negative reactions toward victims (e.g., "In today's society it is important that one not be perceived in any manner as thinking negatively about people who have faced 
misfortune or ill-treatment"). Two MCPRS items (4 and 17) could not be suitably adapted and were not included. All remaining items retained their original wording. The 15 adapted MCPRS items exhibited good internal consistency $(\alpha=.87, M=4.29, S D=0.89) .^{5}$

Participants then read a brief scenario in which a young woman describes how she caught a severe virus while working in a care home, leading to a spell in hospital and severe disruption to her university studies (adapted from Harvey, Callan, \& Matthews, 2014). Participants then rated their overall impression of the woman in both relative ("How negative-to-positive would you evaluate Jenny as a person compared to how negative-topositive you would evaluate the average university student"; $0=$ Very negatively compared to the average student; $10=$ Very positively compared to the average student) and absolute terms ("How negative-to-positive would you evaluate Jenny"; $0=$ Very negatively; $10=$ Very positively). Prior to analysis, all ratings were rescaled from 1-11 and reverse-scored such that higher values indicate more negative evaluations. The order of relative and absolute items was randomized across participants. Finally, participants answered a manipulation check ("In the blog post you read, was Jenny hospitalized due to her infection and, as a result, missed a lot of university"; Yes, No, I can't remember, or It didn't say).

\section{Results and Discussion}

We performed a multilevel analysis using the Ime4 and ImerTest packages in R. Participants ratings were regressed onto scores on the MCPRS (mean-centered), Rating Type (absolute vs. relative, coded as -0.5 and +0.5 ) and the MCPRS $X$ Rating Type interaction. We included random intercepts by participants.

Absolute and relative ratings of the victim were significantly correlated, $r=.68, p<$ .001 . Consistent with our previous studies, there was a significant main effect of Rating Type, such that participants evaluated the victim more negatively using relative vs. absolute scales, $b=.70$, se $=0.11,95 \%$ Wald Cl $[0.49,0.92] ; t(221)=6.51, p<.001$ (See Figure 2). This main effect was qualified by a significant MCPRS X Rating Type interaction, $b=.32$, se $=0.12$, $95 \%$ Wald $\mathrm{Cl}[0.49,0.92] ; t(221)=2.58, p=.01$. A model also including the effect of order of ratings revealed no significant effect of order, $b=-0.21$, se $=.25, t(220)=-0.83, p=40$.

Follow-up analyses to the interaction showed that the effect of relative vs. absolute ratings on derogation of the victim was stronger at higher MCPRS $(+1 S D), b=.99$, se $=0.12$, $95 \%$ Wald CI $[0.68,1.29] ; t(221)=6.42, p<.001$, than at lower MCPRS $(-1 S D), b=.42$, se = $0.15,95 \%$ Wald $\mathrm{Cl}[0.12,0.72] ; t(221)=2.75, p=.006$. To summarize, the Study 4 findings show that the effect of scale type varies as a function of the motivation to suppress negative reactions toward victims, such that absolute and relative ratings diverged to a greater extent amongst people higher in the motivation to avoid negative responses to victims.

\footnotetext{
${ }^{5}$ This measure and the mean normative acceptability of expressing negative feelings toward a variety of victim groups (victims of rape, robbery, assault, fraud, viral infections, natural disasters, freak accidents and cybercrime; cf. Study 1) were significantly correlated $(r=-.41, p<.001)$ in a separate validation study of the revised MCPRS using Mechanical Turk participants ( $N=96, M_{a g e}=36.46,44 \%$ female).
} 


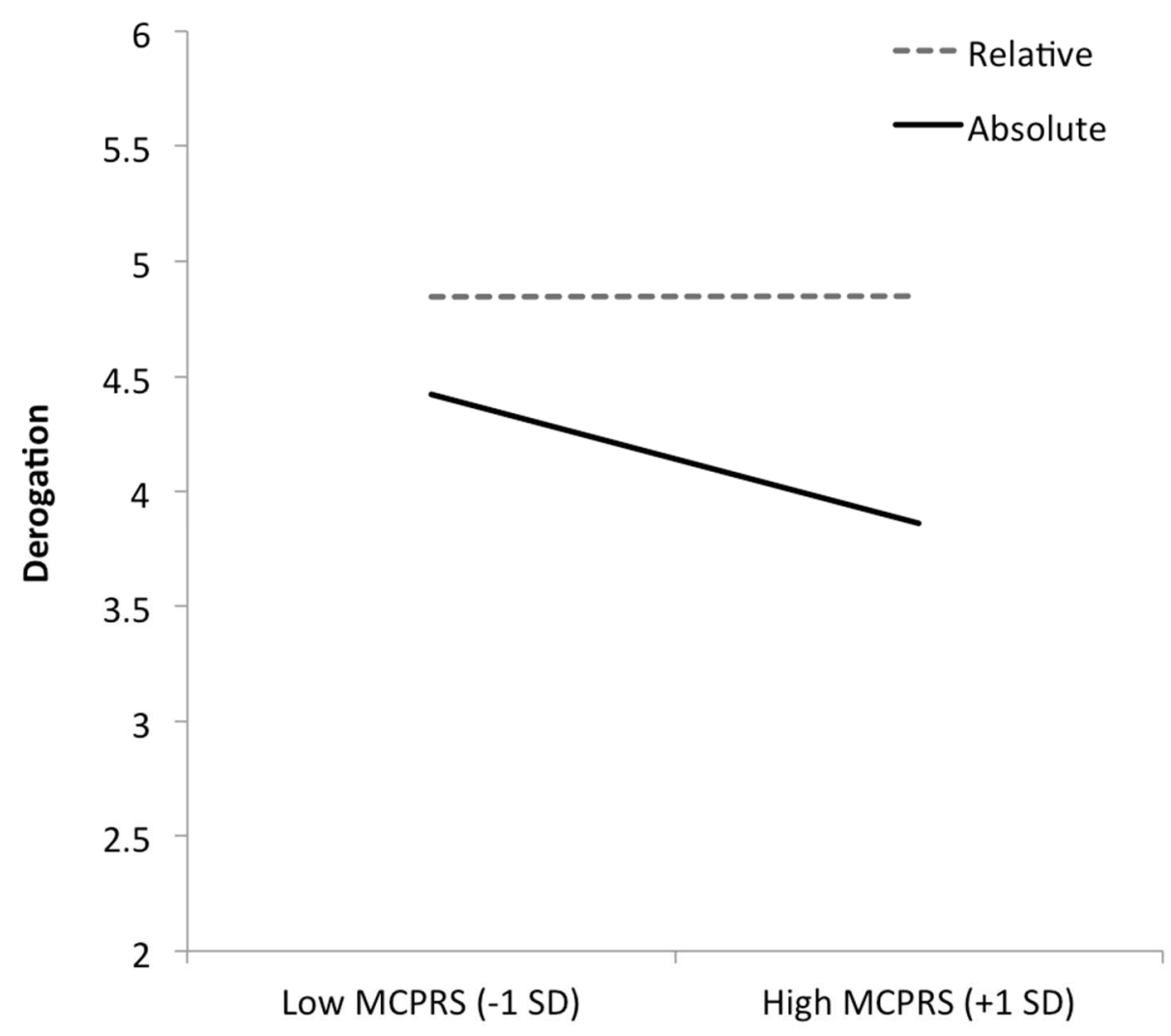

Figure 2. The effect of relative vs. absolute ratings of the victim's character at lower (-1SD) and higher (+ $1 S D$ ) levels of Motivation to Control Prejudiced Reactions (MCPRS) to victims.

\section{General Discussion}

We suggested that relative versus absolute measures are less susceptible to the influence of social norms or personal standards that inhibit the expression of negative reactions to innocent victims, and therefore can be expected to show more negative character ratings. We provided evidence for this line of reasoning across five studies. In Study 1, we found that social norms proscribe the expression of negative feelings toward innocent victims.

Participants believed that it was normatively unacceptable to express negative feelings toward any of the victim groups we examined, and the evaluations which victim and nonvictim groups received were strongly related to social norms-normatively unacceptable targets of negativity, such as victims, received more favorable evaluations. Our Study 1 findings, then, support the notion that evaluations of victims are related to social norms that proscribe negative reactions toward them.

In Studies $2 a$ and $2 b$, evaluations of an accident victim made relative to either the average student $(2 a)$ or the self $(2 b)$ versus absolute ratings showed more derogation only under conditions where observers were theoretically motivated to engage in derogation, and where doing so would contravene social norms (i.e., under high just-world threat/when the victim was innocent). Study 3 partially replicated these results using an alternative 
manipulation of just-world threat-specifically, bad (vs. good) fortuitous outcomes. The interactions we observed in Studies $2 a, 2 b$ and 3 show that relative scales do not simply lead participants to select higher values in any given context-under non-just world threatening conditions, relative ratings were either more favorable than absolute ratings (Study 2a), the same as absolute ratings (Study 2 b), or less favorable but by a smaller margin than under just-world threatening conditions (Study 3). In Study 4, drawing on research and theorizing on prejudice suppression (Crandall, Eshleman, \& O'Brien, 2002; Dunton \& Fazio, 1997), we found that the chronic motivation to comply with social norms and personal standards proscribing the expression of negative feelings toward victims modulated the difference between relative and absolute measures.

\section{Social Norms and the Justification and Suppression of Victim Derogation}

In Crandall and Eshleman's (2003) Justification and Suppression Model (JSM), genuine prejudice does not occur in raw form, but is modified by processes of suppression and justification that, respectively, inhibit or facilitate the emergence of prejudice. Expressed prejudice hence depends on a combination of social, situational (e.g., social norms), and dispositional (e.g., beliefs and values) factors that discourage its expression, or which rationalize or disguise prejudice and allow for it to emerge in an indirect or covert form. For example, a person may suppress prejudice against black people in contexts where antiprejudice social norms are strong or salient (e.g., at a university; in interactions with Black people), but in a situation where norms are weaker or ambiguous (e.g., down the pub with mates) they might tell racially-loaded jokes or express support for discriminatory social policies (Crandall, Blanchard, Brigham, \& Vaughn, 1994; Crandall, Eshleman, \& O’Brien, 2002).

A key implication of the JSM is that expressed and experienced prejudice are rarely, if ever, a veridical reflection of a person's true, underlying prejudice, due to the moderating influence of suppression and justification. We suggest that the same logic applies to victim derogation. To the extent that people are influenced by social norms and personal standards that proscribe negative reactions toward innocent victims, derogation, as it is commonly measured (i.e., absolute self-report scales), is not an unambiguous, veridical reflection of the motivation to derogate. This interpretation is supported by our Study 4 findings showing that the chronic tendency to suppress negative feelings toward victims diminishes absolute levels of derogation. That relative levels of derogation were not influenced in this way suggests that relative scales are less suppression-prone, and perhaps also indicates that participants were similarly motivated to derogate irrespective of the tendency to suppress. Relatedly, our findings in Studies $2 \mathrm{a}$ and $2 \mathrm{~b}$ underscore that people are prone to evaluate victims in highly negative terms under conditions where it is normatively appropriate to do so-that is, when they are unambiguously responsible for their own suffering. 


\section{Relative Measures as Covering}

Relative scales might be conceived as providing a form of psychological cover, allowing for the motivation to derogate the victim to be released in a disguised form that does not overtly conflict with social norms or personal standards. Covering has been described as "the process by which the underlying prejudice that motivates an emotion, behavior or cognition is obscured by focusing attention on a plausible alternative motivation that is socially or personally acceptable" (Crandall \& Eshleman, 2003, p. 428). Covering allows for the release of prejudice under the guise of neutral, socially acceptable or benignly motivated behavior, for example by attributing prejudiced behavior to the requirements of a social role, or to self-interested goals. Working as a police officer, for example, may provide cover for prejudice to emerge via the discriminatory use of stop and search powers, and personal preferences can be invoked to justify avoiding interaction with persons whom one is prejudiced against. Snyder, Kleck, Strenta, and Mentzer (1979), for example, found that participants chose to avoid a physically disabled confederate more often when doing so was construed as a choice between seeing a different (vs. the same) movie in a different theatre. Presumably, the ambiguity as to whether the participant was deliberately avoiding the disabled person or indulging their personal preferences provided cover for their discriminatory behavior.

We suggested at the outset that relative measures render a person's true feelings toward a victim ambiguous, but they might also provide cover for derogation by reframing the context and purpose of judgment. Making an unfavorable social comparison is perhaps less clearly transgressive of social norms than is providing an overtly negative, absolute evaluation of a victim, because comparisons need not be construed as serving an exclusively evaluative purpose. Rather, relative scales could be interpreted more in terms of describing the relationship between a target and comparison referent on some attribute, and less in terms of evaluating the target, per se. This ambiguity in framing could cover the motivation to derogate-unfavorable comparisons may be attributed to a motivation to accurately describe the relationship between the victim and comparison target on the attribute under consideration. If an individual were to be challenged regarding their unfavorable relative judgement, they could justify their evaluation by describing the victim as atypical of students, or by describing the self as particularly responsible compared to one's peers. Relatedly, and in line with the findings of Olson et al. (2007), the verbal explanations participants gave for their scale responses in Studies $2 \mathrm{a}$ and $2 \mathrm{~b}$ show that, whereas absolute responses were explained almost exclusively in terms of attributions toward the victim (e.g., "He was jaywalking and crossed in front of moving traffic which was stupid and careless"), relative responses were often explained in terms of social comparisons (e.g., "I answered the questions the way I did because I would never cross the road with a no walking sign").

\section{Summary and Conclusions}


Akin to prejudice, social norms and personal standards proscribing negative reactions toward victims appear to mute the expression of victim derogation. In a similar manner that people suppress counter-normative prejudices, they may also suppress counter-normative reactions toward victims. We have speculated that relative measures provide a form of cover, allowing for victim derogation to manifest in an ambiguous and covert form that does not openly contravene social norms or personal standards regarding the appropriate treatment of victims. Relative measures may therefore provide a more accurate picture of the underlying motivation to derogate, than do absolute measures, insofar as they are less prone to the influence of these factors.

Future research should seek to more directly address how the properties of relative measures act to mitigate suppression. For example, do relative measures render a person's true attitudes more ambiguous for other persons or the self, as we have argued? Furthermore, to what extent do relative measures mitigate suppression by obscuring the motivation to derogate from either the self or from other persons? The suppression of derogation may result from public compliance to social norms regarding the treatment of victims, from a personal motivation to treat victims in a fair, rational and sympathetic manner, or to some degree from either social pressures or personal motivations.

The present findings echo research on "shifting standards" (Biernat, Manis \& Nelson, 1991) showing that judgments of orthogonal social categories (e.g., men vs. women) differ to a greater degree on objective (e.g., height in centimeters) than absolute measures (e.g., short/tall judgments). When judgments are anchored in stereotypes, for example "women are shorter than men", subjective labels such as "average height" carry a different meaning for either group, and hence objective measures can reveal stereotyping effects that are attenuated on absolute measures. The phenomenon we examined, however, is conceptually and empirically distinct from shifting standards. Although non-innocent (versus innocent) victims are potentially stereotyped as more careless etc., our results do not conform to this model. Whereas shifting standards implies that absolute (relative) measures should converge (diverge) across innocent and non-innocent conditions, Studies $2 \mathrm{a}$ and $2 \mathrm{~b}$ revealed the inverse trend.

A further issue concerns the role of the specific comparison referents employed in relative measures. Insofar as referents (e.g., the self, the average student) are evaluated differently, evaluations of a target should vary depending on the particular referent employed (Goffin \& Olson, 2011). Goffin and Olson (2011) suggest that judgments will be influenced by raters' familiarity with a referent, whether it is an individual or group, and in the latter case, its heterogeneity on the attribute assessed. Future research should seek to systematically examine the influence of these particular properties of comparison referents in the context of victim derogation.

Finally, our reasoning suggests that the present findings should generalize to other contexts in which persons are motivated to express an attitude that is proscribed by social norms or personal standards. Future research could examine, for example, whether absolute and relative measures of racial prejudice differ depending on contextual norms or 
personal values pertaining to the acceptability of prejudice. The present findings underscore that relative measures may be a useful tool in this domain, insofar as they are less suppression-prone than traditional self-report measures, and may have practical advantages over implicit measures of prejudice. 


\section{References}

Baguley, T. (2012). Calculating and graphing within-subject confidence intervals for ANOVA. Behavior Research Methods, 44, 158-175.

Bates, D., Maechler, M., Bolker, B., \& Walker, S. (2015). Fitting Linear Mixed-Effects Models Using Ime4. Journal of Statistical Software, 67 (1), 1-48.

Blanchard, F. A., Crandall, C.S., Brigham, J. C., \& Vaughn, L. A. (1994). Condemning and condoning racism: A social context approach to interracial settings. Journal of Applied Psychology, 79, 993-997.

Brown, J. D. (1986). Evaluations of self and others: Self-enhancement biases in social judgments. Social Cognition, 4, 353-376.

Buhrmester, M., Kwang, T., \& Gosling, S. D. (2011). Amazon's Mechanical Turk: A new source of inexpensive, yet high-quality, data?. Perspectives on Psychological Science, 6, 3-5.

Burczyk, K., \& Standing, L. (1989). Attitudes towards rape victims: Effects of victim status, sex of victim, and sex of rater. Social Behavior and Personality: An International Journal, $17,1-8$.

Callan, M. J., Dawtry, R. J., \& Olson, J. M. (2012). Justice motive effects in ageism: The effects of a victim's age on observer perceptions of injustice and punishment judgments. Journal of Experimental Social Psychology, 48, 1343-1349.

Callan, M. J., Kay, A. C., \& Dawtry, R. J. (2014). Making sense of misfortune: Deservingness, self-esteem, and patterns of self-defeat. Journal of Personality and Social Psychology, $107,142-162$.

Callan, M. J., Harvey, A. J., Dawtry, R. J., \& Sutton, R. M. (2013). Through the looking glass: Long-term goal focus increases immanent justice reasoning. British Journal of Social Psychology, 52, 377-385.

Callan, M. J., Harvey, A. J., \& Sutton, R. M. (2014). Rejecting victims of misfortune reduces delay discounting. Journal of Experimental Social Psychology, 51, 41-44.

Callan, M. J., Powell, N. G., \& Ellard, J.H. (2007). The consequences of victim physical attractiveness on reactions to injustice: The role of observers' belief in a just world. Social Justice Research, 20, 433-456.

Callan, M. J., Shead, N. W., \& Olson, J. M. (2009). Foregoing the labor for the fruits: The effect of just world threat on the desire for immediate monetary rewards. Journal of Experimental Social Psychology, 45, 246-249. 
Correia, I., \& Vala, J. (2003). When will a victim be secondarily victimized? The effect of observer's belief in a just world, victim's innocence and persistence of suffering. Social Justice Research, 16, 379-400.

Crandall, C. S., \& Eshleman, A. (2003). A justification-suppression model of the expression and experience of prejudice. Psychological Bulletin, 129, 414-446.

Crandall, C. S., Eshleman, A., \& O'Brien, L. (2002). Social norms and the expression and suppression of prejudice: the struggle for internalization. Journal of Personality and Social Psychology, 82, 359-378.

Crosby, F., Bromley, S., \& Saxe, L. (1980). Recent unobtrusive studies of Black and White discrimination and prejudice: A literature review. Psychological Bulletin, 87, 546-563.

Deal, M. (2007). Aversive disablism: Subtle prejudice toward disabled people. Disability \& Society, 22, 93-107.

DeBono, A., Shmueli, D., \& Muraven, M. (2011). Rude and inappropriate: The role of selfcontrol in following social norms. Personality and Social Psychology Bulletin, 37, 136146.

Delacre, M., Lakens, D., \& Leys, C. (in press). Why psychologists should by default use Welch's $t$-test instead of Student's t-test. International Review of Social Psychology.

Devine, P. G., \& Monteith, M. J. (1993). The role of discrepancy associated affect in prejudice reduction. In D. M. Mackie \& D. L. Hamilton (Eds.), Affect, cognition, and stereotyping (pp. 317-344). New York: Academic Press.

Dunton, B. C., \& Fazio, R. H. (1997). An individual difference measure of motivation to control prejudiced reactions. Personality and Social Psychology Bulletin, 23, 316-326.

Ellard, J. H., Harvey, A., \& Callan, M. J. (2016). The justice motive: History, theory, and research. In C. Sabbagh \& M. Schmitt (Eds.), Handbook of Social Justice Theory and Research (pp. 127-143). New York: Springer.

Feather, N. T. (2006). Deservingness and emotions: Applying the structural model of deservingness to the analysis of affective reactions to outcomes. European Review of Social Psychology, 17, 38-73.

Goffin, R. D., \& Olson, J. M. (2011). Is it all relative? Comparative judgments and the possible improvement of self-ratings and ratings of others. Perspectives on Psychological Science, 6, 48-60.

Hafer, C. L., \& Bègue, L. (2005). Experimental research on just-world theory: problems, developments, and future challenges. Psychological Bulletin, 131, 128-167. 
Harvey, A. J., Callan, M. J., \& Matthews, W. J. (2014). How much does effortful thinking underlie observers' reactions to victimization? Social Justice Research, 27, 175-208.

Judd, C. M., Westfall, J., \& Kenny, D. A. (2012). Treating stimuli as a random factor in social psychology: A new and comprehensive solution to a pervasive but largely ignored problem. Journal of Personality and Social Psychology, 103, 54-69.

Katz, I., \& Hass, R. G. (1988). Racial ambivalence and American value conflict: Correlational and priming studies of dual cognitive structures. Journal of Personality and Social Psychology, 55, 893-905.

Krueger, J. (1998). Enhancement bias in descriptions of self and others. Personality and Social Psychology Bulletin, 24, 505-516.

Kuznetsova, K., Brockhoff, P. B., \& Christensen, R. H. B. (2016). ImerTest: Tests in Linear Mixed Effects Models. R package version 2.0-30. http://CRAN.Rproject.org/package=ImerTest

Lerner, M. J. (1965). Evaluation of performance as a function of performer's reward and attractiveness. Journal of Personality and Social Psychology, 1, 355-360.

Lerner, M. J. (1980). The belief in a just world: A fundamental delusion. US: Springer.

Lerner, M. J. (1987). Integrating societal and psychological rules of entitlement: The basic task of each social actor and fundamental problem for the social sciences. Social Justice Research, 1, 107-125.

Lerner, M. J. (1998). The two forms of belief in a just world. In Lerner, M. J., \& Montada, L. (Eds.), Responses to victimizations and belief in a just world (pp. 247-269). US: Springer.

Lerner, M. J. (2003). The justice motive: Where social psychologists found it, how they lost it, and why they may not find it again. Personality and Social Psychology Review, 7, 388399.

Lerner, M. J., \& Simmons, C. H. (1966). Observer's reaction to the" innocent victim": compassion or rejection?. Journal of Personality and Social Psychology, 4, 203-210.

Meertens, R. W., \& Pettigrew, T. F. (1997). Is subtle prejudice really prejudice? The Public Opinion Quarterly, 61, 54-71.

Olson, J. M., Goffin, R. D., \& Haynes, G. A. (2007). Relative versus absolute measures of explicit attitudes: Implications for predicting diverse attitude-relevant criteria. Journal of Personality and Social Psychology, 93, 907-926.

Peer, E., Brandimarte, L., Samat, S., \& Acquisti, A. (2017). Beyond the Turk: Alternative platforms for crowdsourcing behavioral research. Journal of Experimental Social Psychology, 70, 153-163. 
Ryan, W. (1971). Blaming the victim. New York: Pantheon

Saarni, C. (1999). The development of emotional competence. New York: Guilford.

Snyder, M. L., Kleck, R. E., Strenta, A., \& Mentzer, S. J. (1979). Avoidance of the handicapped: an attributional ambiguity analysis. Journal of Personality and Social Psychology, 37, 2297-2306.

Stangor, C., Sechrist, G. B., \& Jost, J. T. (2001). Changing racial beliefs by providing consensus information. Personality and Social Psychology Bulletin, 27, 486-496.

Weiner, B. (1995). Inferences of responsibility and social motivation. In M. P. Zanna (Ed.), Advances in Experimental Social Psychology (Vol. 27, pp. 1-47). New York: Academic Press. 